\title{
The effect of the COVID-19 pandemic on the patient safety attitude of medical students
}

Jisoo Lee ${ }^{1}$ and Kyung Hye Park ${ }^{2,3}$

Departments of ${ }^{1}$ Medicine and ${ }^{2}$ Medical Education, Yonsei University Wonju College of Medicine, and ${ }^{3}$ Department of Emergency Medicine, Wonju Severance Christian Hospital, Wonju, Korea

Purpose: This study aimed to examine the differences in scores of the Attitude to Patient Safety Questionnaire (APSO) by medical students before and after the outbreak of COVID-19.

Methods: In total, 97 and 118 medical students completed patient safety courses at Yonsei University Wonju College of Medicine in 2019 and 2020, respectively. In 2019, the course was conducted using traditional learning in the classroom, whereas, in 2020, most of the classes were conducted using non-face-to-face learning methods.

Results: In 2019 and 2020, 49 and 53 students responded to the APSO. Only one item "Patients are not really aware of how safe their care is" had a lower score in 2020 than in 2019.

Conclusion: Although the total APSO score did not differ between 2019 and 2020, the students in 2020 might have a poor understanding of the role of patients in medical errors.

Key Words: COVID-19, Distance education, Medical students, Patient safety

\section{Introduction}

Coronavirus disease 2019 (COVID-19) and social distancing have affected clinical clerkship, with fewer patients visiting university hospitals and parents of pediatric patients tending to avoid medical students $[1,2]$. Since medical students had limited chances to participate in clinical practice, they also had fewer chances of communicating with patients and meeting with clinical professors for feedback [1]. In addition, clinical practice has either been replaced by simulation or the time spent in hospitals has been limited for medical students in clinical clerkship when clinical practice is conducted $[3,4]$.

Most medical education classes have switched to a non-face-to-face format. Full-scale online classes are conducted instead of classroom lectures in all medical education phases in most medical schools. While most students prefer online classes, only 13\% of teachers do [5]. Our medical college launched a patient safety course in 2019 for third-year medical students, who took this course during their first clinical clerkship. In the patient safety course, attaining knowledge, learning skills and attitudes, and understanding the experiences of role models and cases during clinical practice are important
Received: July 14, 2021 - Revised: August 5, 2021 • Accepted: August 9, 2021 Corresponding Author: Kyung Hye Park (https://orcid.org/0000-0002-5901-6088) Department of Medical Education, Yonsei University Wonju College of Medicine, 20 Ilsan-ro, Wonju 26426, Korea

Tel: +82.33.741.0242 Fax: +82.33.742.5034 email: erdoc@yonsei.ac.kr
Korean J Med Educ 2021 Sep; 33(3): 227-232

https://doi.org/10.3946/kjme.2021.202

eISSN: $2005-7288$

(C) The Korean Society of Medical Education. All rights reserved. This is an open-access article distributed under the terms of the Creative Commons Attribution Non-Commercial License (http:// creativecommons.org/licenses/by-nc/3.0/), which permits unrestricted non-commercial use, distribution, and reproduction in any medium, provided the original work is properly cited. 
learning methods. Before COVID-19, all patient safety classes were conducted offline but, since 2020, most classes have been online. Since the total time of bedside teaching and clinical practice in the hospital was reduced, students' clinical experience was limited when compared to what it would have been before COVID-19. Research findings on the effects of reduced clinical practice and online classes on a patient safety course before and after the COVID-19 outbreak are limited, and the learning effect on students will likely differ. Therefore, we aim to compare the attitude toward patient safety measured at the end of the patient safety course between 2019 and 2020 in third year medical students.

\section{Methods}

A total of 97 and 118 third-year medical students in 2019 and 2020, respectively, completed the course at Yonsei University Wonju College of Medicine. Its contents are based on the World Health Organization Patient Safety Curriculum for Medical Schools and the course is conducted 2 hours per week over 16 weeks [6]. In 2020, error disclosure exercises and interprofessional education were conducted offline as before [7] (Table 1). When students finished the course, they were encouraged to voluntarily participate in the survey of the Attitudes

Table 1. Comparison of Teaching and Learning Methods in the Patient Safety Course Between 2019 and 2020

\begin{tabular}{|c|c|c|}
\hline Topics & 2019 & 2020 \\
\hline The importance of patient safety & $\begin{array}{l}\text { Flipped classroom; video lecture and group } \\
\text { discussion in the classroom }\end{array}$ & $\begin{array}{l}\text { Real-time online lecture and group discussion, } \\
\text { writing paper }\end{array}$ \\
\hline Human factors and system & $\begin{array}{l}\text { Flipped classroom; video lecture and group } \\
\text { discussion in the classroom }\end{array}$ & $\begin{array}{l}\text { Real-time online lecture and group discussion, } \\
\text { writing paper }\end{array}$ \\
\hline Understanding and learning from errors & $\begin{array}{l}\text { Flipped classroom; video lecture and group } \\
\text { discussion in the classroom }\end{array}$ & $\begin{array}{l}\text { Real-time online lecture and group discussion, } \\
\text { writing paper }\end{array}$ \\
\hline Quality improvement methods & $\begin{array}{l}\text { Flipped classroom; video lecture and group } \\
\text { discussion in the classroom }\end{array}$ & $\begin{array}{l}\text { Real-time online lecture and group discussion, } \\
\text { writing paper }\end{array}$ \\
\hline $\begin{array}{l}\text { Interprofessional collaboration, team } \\
\text { communication }\end{array}$ & $\begin{array}{l}\text { Interactive theater and group discussion with } \\
\text { fourth-year nursing students in the classroom } \\
\text { after video lectures [7]. }\end{array}$ & $\begin{array}{l}\text { Small group simulation (role-play and } \\
\text { high-fidelity simulation) with fourth-year } \\
\text { nursing students after video lectures }\end{array}$ \\
\hline Open disclosure & $\begin{array}{l}\text { Time-in time-out group exercise with } \\
\text { standardized patient after video lecture }\end{array}$ & $\begin{array}{l}\text { Time-in time-out group exercise with } \\
\text { standardized patient after video lecture }\end{array}$ \\
\hline Patient safety and infection control & $\begin{array}{l}\text { Flipped classroom; video lecture, group } \\
\text { discussion, trying on protection suit in the } \\
\text { classroom }\end{array}$ & $\begin{array}{l}\text { Video lecture and real-time online group } \\
\text { discussion, writing paper }\end{array}$ \\
\hline Medication safety & $\begin{array}{l}\text { Flipped classroom; video lecture and group } \\
\text { discussion in the classroom }\end{array}$ & $\begin{array}{l}\text { Real-time online lecture and group discussion, } \\
\text { writing paper }\end{array}$ \\
\hline Patient safety and invasive procedures & $\begin{array}{l}\text { Flipped classroom; video lecture and group } \\
\text { discussion in the classroom }\end{array}$ & Video lecture and writing paper \\
\hline $\begin{array}{l}\text { Communication techniques for } \\
\text { health-care teams }\end{array}$ & $\begin{array}{l}\text { Flipped classroom; video lecture and role-play } \\
\text { in the classroom }\end{array}$ & $\begin{array}{l}\text { Video lecture and submitting voice recording of } \\
\text { patient presentation as homework }\end{array}$ \\
\hline $\begin{array}{l}\text { Radiation risk communication, engaging } \\
\text { with patients and carers }\end{array}$ & $\begin{array}{l}\text { Flipped classroom; video lecture and role-play } \\
\text { in the classroom }\end{array}$ & Video lecture and writing paper \\
\hline Diagnostic error & $\begin{array}{l}\text { Flipped classroom; video lecture and role-play } \\
\text { in the classroom }\end{array}$ & Video lecture and writing paper \\
\hline $\begin{array}{l}\text { Introduction of patient safety activities } \\
\text { in our hospital }\end{array}$ & Lecture in the classroom & Video lecture \\
\hline $\begin{array}{l}\text { Presentation of quality improvement } \\
\text { activity }\end{array}$ & $\begin{array}{l}\text { Each group's presentation in the classroom (17 } \\
\text { groups) }\end{array}$ & $\begin{array}{l}\text { Each group's poster display without oral } \\
\text { presentation (17 groups) }\end{array}$ \\
\hline Written examination & In the classroom & In the classroom \\
\hline
\end{tabular}




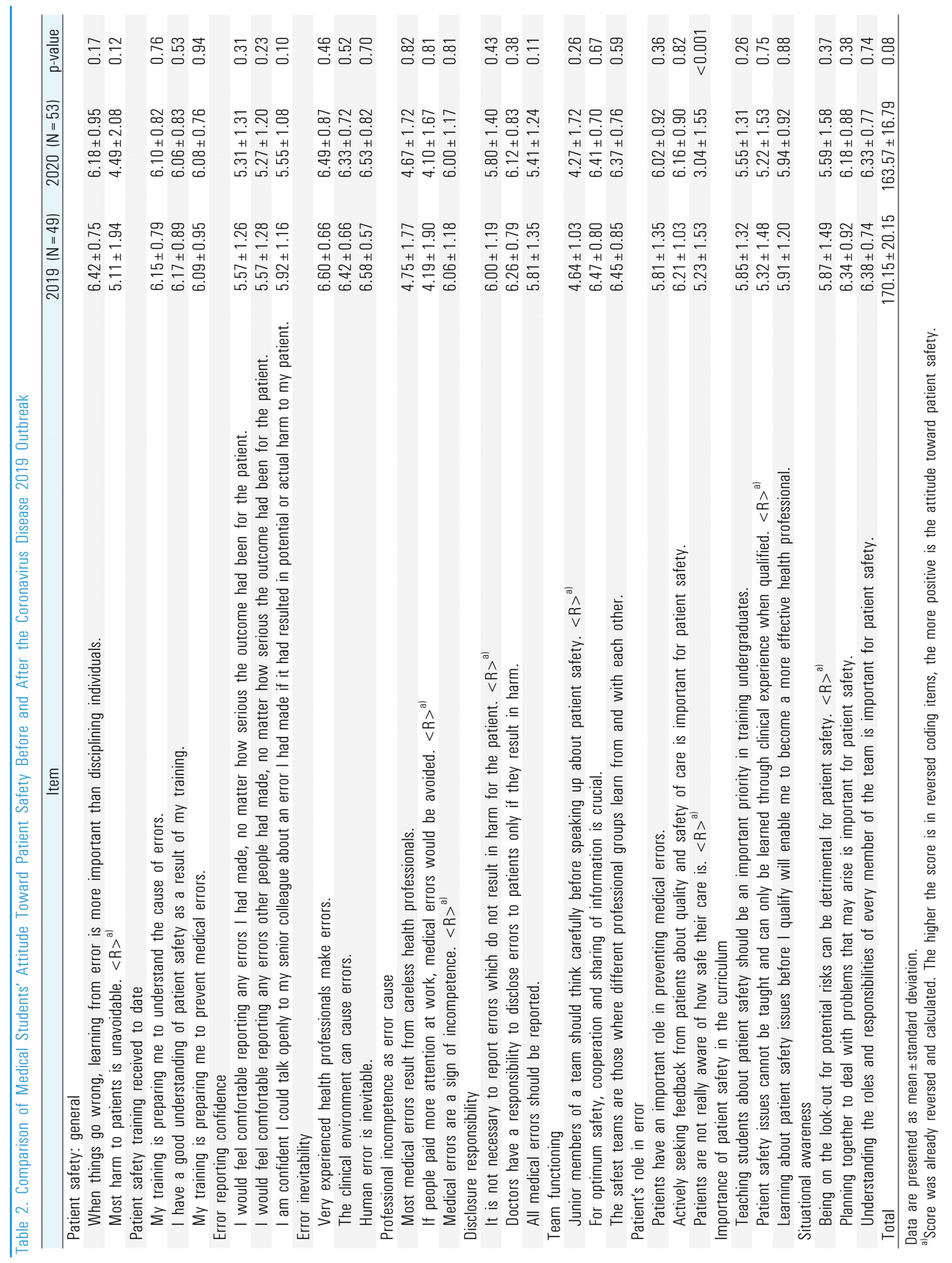


to Patient Safety Questionnaire (APSQ) to measure their attitude to patient safety as one of the elements of course evaluation.

The APSQ was developed by Carruthers et al. [8] and translated into Korean [9]. It comprises 29 items rated on a 7-point Likert scale (7=completely agree). Several items should be reverse scored. The higher the scores were, the more affirmative or positive the responses were. The APSQ scores were compared using the t-test. IBM SPSS ver. 23.0 (IBM Corp., Armonk, USA) software was used for the analyses; significance was set at $\mathrm{p}<0.05$.

This study was approved by the Institutional Review Board of Yonsei University Wonju Christian Severance Hospital (CR320182). Informed consent was waived.

\section{Results}

In total, 49 students (50.5\%) responded in 2019 and 53 students (44.9\%) responded in 2020. There were no differences in total scores between the two groups (170.15 \pm 20.15 versus $163.57 \pm 16.79, \mathrm{p}=0.08)$. The item with the lowest score was "If people paid more attention at work, medical errors would be avoided" in both groups (4.19 $\pm 1.90,4.10 \pm 1.67$, respectively). The item with the highest score was "Very experienced health professionals make errors" in 2019, and "Human error is inevitable" in 2020 (6.60 $\pm 0.66,6.53 \pm 0.82$, respectively); both items belong to "error inevitability." The only difference in the APSQ item was "Patients are not really aware of how safe their care is," which was $3.04 \pm 1.55$ in 2019 and $5.23 \pm 1.53$ in $2020(\mathrm{p}<0.001)$ (Table 2).

\section{Discussion}

We investigated the differences in patient safety attitudes after the completion of the patient safety course by third-year medical students. The total APSQ score was approximately 7 points lower on average among respondents in 2020, but there was no statistical difference. The lack of a significant difference between the total APSQ scores and the same highest and lowest scored items could imply that the achievement of the patient safety outcome was similar in 2020, although it was in the midst of the COVID-19 pandemic. This could be attributed to the fact that classes were conducted on all topics of the patient safety course, and although the time spent in the hospital or encountering patients decreased due to the contraction of clinical practice, the clinical practice period of each department was maintained.

The only item with a difference in the APSQ was "Patients are not really aware of how safe their care is" from the category "Patient's role in error," and the scores of students in 2020 were exceptionally lower compared to other items. This item score was $5.10 \pm 1.23$ in a study of Park et al. [9] in which the survey of APSQ was conducted in 2018. Although this score is similar to the score in 2019, the score in 2020 was significantly low. In Mexico, the effect of the patient safety course among fourth-year medical students was investigated during the COVID-19 pandemic. No survey items were found to be directly related to patient's role in error. Mexican medical students disapproved of just culture [10]. Thus, the patient's role in error could be considered a part of the patient safety culture. Our findings may be attributed to the fact that students had reduced chances of meeting patients during COVID-19, and they underestimated the role of patients. In our medical school, six to seven 
students were assigned to one clinical department, but the number of students who could gather at a time was limited and the opportunities to meet patients were reduced. For example, only one student was allowed to observe the surgery; in some clinical departments, they did not participate in ward rounds. During clinical clerkship, students acquire knowledge, skills, and attitudes by forming relationships with patients [11], and peer learning takes place [12]. However, due to the COVID-19-restrictions, their opportunities to observe actual doctors' practice and share in clinical and professional experience were not enough, making it difficult to learn about physical examinations and communicate with patients [4]. For patient safety, experiential learning through clinical practice is important, but there seems to be a limit to this. Medical students felt that they had detracted from authentic communication with patients during clinical clerkship [13]. Senior medical students in the United Kingdom reported that the cancellation or postponement of objective structured clinical examination, assistantship, and electives due to COVID-19 affected their preparation for the first year of training [14].

Flipped learning in the classroom changed to online lectures. Student-centered methods such as flipped learning had a better effect on learning, regardless of achievements such as grades [12]. On the other hand, non-face-to-face classes were preferred because students could attend from any place and re-learning was convenient when there was a video lecture [5]. Therefore, considering that the final APSQ total score had no difference, it seems that the students achieved learning outcomes in terms of patient safety regardless of the teaching and learning methods.

This study had a few limitations. Because students were asked to participate in the survey voluntarily, about half of the students we approached did not respond; thus, we do not know their APSQ scores. Moreover, it would be difficult to generalize this result because it is a comparison of patient safety at one school. Because this is a retrospective study, it is difficult to distinguish which was more responsible, the contraction of clinical practice due to the unprecedented event of COVID-19 pandemic or the intentional intervention by which the clinical practice process was converted to non-faceto-face lectures. Further qualitative research is needed to identify other factors affecting patient safety attitude.

The medical education environment has changed drastically from pre COVID-19 times. Based on the findings of this study, medical students rated the patient's role in error as poor, which might be due to the reduced clinical practice. Knowledge can be imparted and learned while maintaining student satisfaction through non-face-to-face instruction but, in essence, the attitudes that must be learned through experiential learning in interactions with patients, professors, and peer-students must be maintained to a similar, preCOVID-19 degree.

\section{ORCID:}

Jisoo Lee: https://orcid.org/0000-0002-4304-9977;

Kyung Hye Park: http://orcid.org/0000-0002-5901-6088

Acknowledgements: None.

Funding: No financial support was received for this study.

Conflicts of interest: No potential conflict of interest relevant to this article was reported.

Author contributions: Conception or design of the work: KHP; data collection, data analysis and interpretation: JL; drafting the article: JL; critical revision of the article: KHP; and final approval of the version to be published: JL, KHP. 


\section{References}

1. Park J, Park H, Lim JE, Rhim HC, Lee YM. Medical students' perspectives on recommencing clinical rotations during coronavirus disease 2019 at one institution in South Korea. Korean J Med Educ. 2020;32(3):223-229.

2. Lee YM, Park KD, Seo JH. New paradigm of pediatric clinical clerkship during the epidemic of COVID-19. J Korean Med Sci. 2020;35(38):e344.

3. Kraakevik JA, Beck Dallaghan GL, Byerley JS, et al. Managing expansions in medical students' clinical placements caused by curricular transformation: perspectives from four medical schools. Med Educ Online. 2021;26(1):1857322.

4. Kasai H, Shikino K, Saito G, et al. Alternative approaches for clinical clerkship during the COVID-19 pandemic: online simulated clinical practice for inpatients and outpatients: a mixed method. BMC Med Educ. $2021 ; 21(1): 149$.

5. Kim JW, Myung SJ, Yoon HB, Moon SH, Ryu H, Yim JJ. How medical education survives and evolves during COVID-19: our experience and future direction. PLoS One. 2020;15(12):e0243958.

6. World Health Organization. WHO patient safety curriculum guide for medical schools. https://apps.who. int/iris/handle/10665/44091. Published 2009. Accessed June 29, 2021.

7. Park YC, Park KH. Interprofessional education program for medical and nursing students: interprofessional versus uniprofessional. Korean J Med Educ. 2021;33(1):1-10.

8. Carruthers S, Lawton R, Sandars J, Howe A, Perry M. Attitudes to patient safety amongst medical students and tutors: developing a reliable and valid measure. Med Teach. 2009;31(8):e370-e376.

9. Park KH, Park KH, Kang Y, Kwon OY. The attitudes of Korean medical students toward patient safety. Korean J Med Educ. 2019;31(4):363-369.

10. López-Hernández LB, Díaz BG, González EO, et al. Quality and safety in healthcare for medical students: challenges and the road ahead. Healthcare (Basel). 2020;8(4):540.

11. Dornan T, Tan N, Boshuizen H, et al. How and what do medical students learn in clerkships?: experience based learning (ExBL). Adv Health Sci Educ Theory Pract. 2014;19(5):721-749.

12. Walpola RL, McLachlan AJ, Chen TF. A scoping review of peer-led education in patient safety training. Am J Pharm Educ. 2018;82(2):6110.

13. Nolan H, Owen K. Qualitative exploration of medical student experiences during the COVID-19 pandemic: implications for medical education. BMC Med Educ. $2021 ; 21(1): 285$.

14. Choi B, Jegatheeswaran L, Minocha A, Alhilani M, Nakhoul M, Mutengesa E. The impact of the COVID-19 pandemic on final year medical students in the United Kingdom: a national survey. BMC Med Educ. 2020; 20(1):206. 